\title{
¿Estamos realmente preparados para proporcionar un cuidado humanizado verdadero?
}

\author{
Are we ready to provide real humanized care?
}

Juan M. Leyva-Moral. ${ }^{1 a}$

Desde hace ya unos años venimos leyendo y escuchando por medios científicos sobre la necesidad de implementar cuidados humanizados en nuestra práctica asistencial. Sin embargo, las evidencias muestran que a pesar de que algunos centros ya se han adherido a prácticas humanizadas obteniendo excelentes resultados ${ }^{(1)}$, aun se observan dificultades en su implementación, resistencias profesionales e institucionales, así como carencias formativas ${ }^{(2)}$.

El cuidado humanizado hace referencia una actitud mental, afectiva y moral que requiere una deconstrucción de los propios esquemas mentales, emocionales, comunicativos y conductuales en las acciones sanitarias otorgando especial protagonismo a los detalles ${ }^{(1,2)}$. En definitiva, el cuidado humanizado requiere del respeto a las creencias de los pacientes para diseñar e implementar cuidado invidualizado y culturalmente competente. Este paradigma del cuidado requiere de un cambio en la cosmovisión de lo que es cuidar y ser cuidado, así como un ejercicio reflexivo y autocrítico de nuestras practicas asistenciales, gestoras, docentes e investigadoras ${ }^{(3)}$. Watson propone 10 pasos para alcanzar este cuidado humanizado y compasivo ${ }^{(4)}$ :

1. Practicar la bondad y honestidad de forma consciente en el acto de cuidar. Piensen en cuán diferentes pueden ser los resultados de una situación asistencial si, por ejemplo, respondemos a nuestro paciente "entiendo que debe ser difícil por lo que estas pasando" a si decimos "este el diagnóstico. Haz lo que te digamos y todo irá bien".

2. Estar presente de forma auténtica y facilitadora. Intenten recordar en cuantas ocasiones hemos atendido a un paciente a la vez que estamos pensando en otras tareas que nos preocupan.

3. Cultivar la espiritualidad yendo más allá del propio yo. Al margen de la religión de cada uno de nosotros, pensemos en qué le preocupa a nuestros pacientes y de qué forma podemos ayudar en su curación, dejando de lado la idea que nosotros somos el centro del proceso.

4. Desarrollar y mantener una relación de confianza. ¿Alguna vez has sentido que un profesional no te transmite confianza? Muy probablemente la respuesta es afirmativa. Piensa ahora qué puede suceder si tus pacientes pierden esa confianza en ti y cuáles pueden ser las consecuencias.

5. Estar presente y dar soporte a la expresión de sentimientos positivos y negativos. Que bien sienta reír a carcajadas o llorar abiertamente cuando uno está alegre o triste, ¿cierto? Piensen por qué en muchas ocasiones no permitimos que nuestros pacientes lloren y les decimos "no llores", "aguanta" o "no pasa nada". Lo hacemos con buena intención, seguro, pero ¿qué impacto tienen estas acciones en el proceso asistencial?.

6. Contemplar y utilizar la creatividad para obtener información durante el proceso asistencial. Hagan un ejercicio de reflexión personal e intenten sentir qué papel ocupan las subjetividades en su práctica diaria. Del mismo modo, ¿qué valor le damos al imaginario social, a las creencias, significados, etc. que nuestros pacientes o compañeros verbalizan?.

\footnotetext{
1.Departamento de Enfermería de la Facultad de Medicina de la Universidad Autónoma de Barcelona, España. 


\section{Implicarse en enseñanzas y aprendizajes genuinos que} contemplen los fenómenos de forma global teniendo siempre en cuenta la perspectiva del otro. De nuevo las subjetividades cobran protagonismo. ¿Cómo podemos ser genuinos si únicamente damos valor a lo objetivo?.

8. Crear ambientes de curación que potencien la integridad, el confort, la dignidad y la paz. Este paso es delicado; aquí necesitamos el compromiso institucional y del gobierno a la hora de distribuir recursos o políticas. Por ejemplo, ¿cuántos de nosotros aceptaríamos hospitales abiertos a las familias $24 \mathrm{~h}$ ? También hay pequeños detalles en nuestra práctica: alzar la voz en los pasillos, atender a pacientes en presencia de terceros, interrupciones repetidas, usar apelativos cariñosos para los que no tenemos permiso, no correr cortinas, dejar puertas abiertas, y un largo etc. Piensen en cuantos ejemplos más ocurren en su práctica diaria.

9. Asistir en las necesidades básicas de forma consciente e intencional, potenciando mente, cuerpo y espíritu. Todos tenemos presente el cuerpo físico, dada la gran influencia del modelo biomédico en nuestras prácticas; pero, ¿qué hacemos para aliviar la mente y el espíritu de nuestros pacientes? ¿hablamos con ellos al respecto? ¿nos sentimos preparados para hacerlo?, ¿lo sentimos realmente necesario?.

10.Estar abierto a aspectos de vida y muerte, incluyendo cudados para el alma tanto del profesional como del paciente. En estrecha relación con el paso anterior ¿hablamos libremente de la muerte con nuestros pacientes? ¿les preguntamos sobre cómo quieren ser cuidados llegado el día? ¿qué papel ocupa la familia en todo esto?

Sobre el papel parece bastante fácil de cambiar nuestra forma de pensar y actuar, pero en la realidad aun siguen observándose algunas actitudes y comportamientos resistentes al respecto. Tal vez sean casos residuales, pero podrían tener el suficiente impacto en los pacientes como para romper la relación terapéutica y de confianza, poniendo en peligro el autocuidado, la adherencia a tratamientos.

Para finalizar pensemos en cómo desearíamos ser cuidados o que cuiden a nuestros seres queridos y compárenlo con como es el cuidado que ustedes facilitan o cómo es el cuidado que sus colegas facilitan. Recojan esas reflexiones y piensen qué pequeños cambios pueden implementar para proporcionar cuidados humanizados.

No se frustren si identifican muchos elementos de cambio; al contrario de lo que pueda estar pensando ahora, es un hallazgo positivo:ha identificado elementos de cambio de forma crítica y reflexiva. Ahora sabe como puede cambiar su práctica. El siguiente nivel es conseguir los aliados necesarios para implementar los cambios necesarios.

\section{REFERENCIAS BIBLIOGRÁFICAS}

1. Galvez Herrer, M., Gomez García, J.M., Martín Delgado, M.C., Ferrero Rodríguez, M., Miembros del Proyecto HU-Cl. Humanización de la Sanidad y Salud Laboral: implicaciones, estado de la cuestión y propuesta del Proyecto HU-Cl. Med Segur 2017; 63 (247): 103-119.

2. Bezerra de Farias, F.B., Vidal, L.L., Rodrigues Farias, R.A., Pedreira de Jesus, A.C. Humanized Care in the ICU: Challenges from the viewpoint of Health Professionals. J. Res Fundam Care 2013; 5(4):635-642

3. Beltrán-Salazar, O. Atención al detalle, un requisito para el cuidado humanizado. Index Enferm 2015; 24(1-2): 49-53

4. Lee, S.M., Palmieri, P.P., Watson, J. Global Advances in human caring literacy. Springer Publishing Company, 2016. New York. 